\title{
Generalized Stochastic Models For Building Performance Evaluation In Nigeria
}

\author{
Sule S., Eme D.B. \\ ${ }^{I}$ Department of Civil and Environmental Engineering, University of Port Harcourt, Rivers State. \\ ${ }^{2}$ Department of Civil and Environmental Engineering, University of Port Harcourt, Rivers State.
}

\begin{abstract}
The performance of a building in service is a function of the human intervention at every stage of a building process. In this paper, a generalized stochastic model is formulated to evaluate the performance of an ongoing construction, a case study of Laboratory Block at College of Continuing Education, University of Port Harcourt, Rivers State, Nigeria. The stochastic parameters employed in the structural reliability estimation were obtained from the non- destructive test carried out on the Laboratory Block. The model was formulated using the working stress design criteria and it was the method invoked in the structural reliability estimate. The geometric index obtained from the formulated model was 2.997 and was compared with the target geometric indices of the various structural members. It was found to be less than the target geometric indices of 4.9 for beams in flexure, 3.6 for beams in shear, 4.5 for slabs and 3.9 for columns under dead- live load combination showing that the structure is not showing promise of satisfactory performance in service and can cause serious accident which may lead to loss of lives and damage of properties on collapse.
\end{abstract}

Keywords: - stochastic model, ongoing construction, stochastic parameters, structural reliability, geometric index

\section{INTRODUCTION}

The rate of building failure in Nigeria is alarming. Accidents, loss of precious lives and damage of properties that often result from building failure and subsequent collapse has made performance evaluation of all ongoing building construction in Nigeria a must [1-5]. Structures once designed and erected must fulfil the intended purpose, must be safe and must be economical both interms of construction and maintenance cost. Structural reliability is the ability of a structure to fulfil the intended purpose. The reliability of concrete components of a building is dependent on the human intervention in the area of regular or periodic maintenance at every stage of a building process [6]. Satisfactory performance of concrete components of a structure can be achieved by keeping to adequate quality control of concrete produced at building construction sites [6]. The use of conventional factor of safety in civil and structural engineering design cannot guarantee structural safety as structural loadings cannot be achieved with certainty. Structural distress such as visible cracks on walls, vibration of floors, corrosion of reinforcement in structural members, etc are signs of structural deterioration and degradation and call for performance evaluation rather than sitting down and watch the building collapse [7-8]. Due to variabilities inherent in structural loadings and design models, the parameters involved in the performance assessment are assumed to behave randomly and stochastically and probabilistic theory has become a very useful approach. Even though it may not have provided solutions to all uncertainties involved in structural loading and design models, it has helped in no small measure in the performance evaluation of most civil and structural engineering facilities [9]. It is believed that the formulated model can help to always predict the reliability status of all ongoing construction at project sites in Nigeria to enhance maximum utilization of buildings and other structural facilities. The evaluation procedure is simple, straightforward and not cumbersome mathematically.

\section{STRUCTURAL RELIABILITY MODEL FORMULATION}

According working stress design criteria,

$\sigma_{i} \leq \sigma_{a i}$

Where:

$\sigma_{i}, \sigma_{a i}=$ Internal stress developed and allowable stress in the structural member respectively.

Failure occurs in a particular structural member when equation (1) is violated and the failure condition is given by:

$P f=P\left(X<\sigma_{a}\right)$

Where: 
$P, X$ represent probability operator and material strength in the structure respectively.

The material strength $X$ is assumed to vary randomly and stochastically and is normally distributed. Therefore equation (2) now transforms to:

$$
P f=\phi\left(\frac{\sigma_{a}-\mu_{x}}{\sigma_{x}}\right)
$$

From equation (3) we have:

$(P f) \phi^{-1}=\frac{\sigma_{a}-\mu_{x}}{\sigma_{x}}=\beta$

Where: $\phi=$ standardized normal distribution function

Where:

$\beta=$ Structural performance or geometric index.

From equation (4), we have:

$\sigma_{a}-\mu_{x}=\beta \sigma_{x}$

From statistical theory,

$\sigma_{x}=\delta_{x} \mu_{x}$

Using equation (6), equation (5) transforms to:

$\sigma_{a}-\mu_{x}=\beta \delta_{x} \mu_{x}$

Dividing both sides of equation (7) by $\mu_{x}$ transforms equation (7) to:

$\frac{\sigma_{a}}{\mu_{x}}-1=\beta \delta_{x}$

From equation (8) we have:

$\frac{\sigma_{a}}{\mu_{x}}-1+\beta \delta_{x}$

According to BS8110 [10],

$\sigma_{a}=0.34 y$

and

$\mu_{x}=0.67 \mu_{y}$

Where:

$y, \mu_{y}=$ cube strength of concrete and mean value of cube strength of concrete respectively.

$\delta_{x}=$ Net coefficient of variation of concrete strength in structure.

According to Ranganathan [2],

$\sigma_{x}=\left(\sigma_{y}^{2}+\sigma_{\text {test }}^{2}+\sigma_{\text {in }- \text { situ }}^{2}\right)$

Where:

$\sigma_{\text {test }}, \sigma_{\text {in-situ }}$ represent the coefficient of variation in concrete testing procedure and in-situ concrete strength variation in structure.

According to Ranganathan [2], $\sigma_{\text {test }}, \sigma_{i n-s i t u}=0.10$ and equation (12) reduces to:

$\sigma_{x}=\sigma_{y}^{2}+0.0125$

$\sigma_{y}$ is a function of the design mix, implying that:

$\sigma_{y}=f$ (design mix)

Using equations (10) and (11), equation (9) can be written as:

$\frac{0.34 y}{0.67 \mu_{y}}=1+\beta \delta_{x}$

From equation (15), we have: 
$\beta=\frac{1}{\delta_{x}}\left(\frac{0.34 y}{0.67 \mu_{y}}-1\right)$

Using equation (16), the geometric index of concrete components of a structure can be estimated.

\section{RESULTS AND DISCUSSION}

The results of Schmidt hammer tests (Table 1) conducted on the Laboratory Block at College of Continuing Education University of Port Harcourt is used to demonstrate the applicability of the formulated structural reliability models.

Table 1: Results of Schmidt hammer test on concrete [11].

\begin{tabular}{|l|l|l|l|l|}
\hline S/No & Location & $\begin{array}{l}\text { Rebound } \\
\text { Hammer } \\
\text { readings }\end{array}$ & $\begin{array}{l}\text { Average } \\
\text { Rebound }\end{array}$ & $\begin{array}{l}\text { Concrete Strength from } \\
\text { Rebound } \\
\text { Test }(\mathbf{y})\end{array}$ \\
\hline 1 & Middle panel & 23,23 & 23 & 18 \\
\hline 2 & Edge panel & 23,23 & 23 & 18 \\
\hline 3 & Beam 2 & 20,20 & 20 & 14 \\
\hline 4 & Slab 2 & 24,24 & 24 & 20 \\
\hline 5 & Slab 1 & 18,19 & 19 & 8 \\
\hline 6 & Beam 1 & 12,12 & 12 & 5 \\
\hline 7 & Staircase & $23.3,19$ & 21.2 & 15 \\
\hline 8 & Middle column & 35,27 & 31 & 29 \\
\hline 9 & Corner column & 27,27 & 27 & 2.5 \\
\hline 10 & Column footing & $12.5,6$ & 9 & 4 \\
\hline & & & & $\mu_{y}=\sum_{i=1}^{10} \frac{y_{i}}{10}=15 \mathrm{~N} / \mathrm{mm}^{2}$ \\
\hline
\end{tabular}

Table 2: Stochastic model [2].

\begin{tabular}{|l|l|l|l|l|l|l|l|}
\hline Variable & Mix & $\begin{array}{l}\text { Specified } \\
\text { strength }\end{array}$ & $\begin{array}{c}\text { Mean }\left(\mu_{y}\right) \\
\left(\mathrm{N} / \mathrm{mm}^{2}\right)\end{array}$ & $\begin{array}{l}\text { Std deviation } \\
\sigma_{y}\left(\mathrm{~N} / \mathrm{mm}^{2}\right)\end{array}$ & $\begin{array}{l}\text { COV }\left(\delta_{y}\right) \\
(\%)\end{array}$ & $\begin{array}{l}\text { Probability } \\
\text { distribution }\end{array}$ & $\begin{array}{l}\text { Quality } \\
\text { control }\end{array}$ \\
\hline $\begin{array}{l}\text { Cube } \\
\text { strength }\end{array}$ & Grade 15 & 15 & 17.56 & 2.69 & 15.33 & Normal & $\begin{array}{l}\text { Design } \\
\text { mix }\end{array}$ \\
\hline
\end{tabular}

From Table1 and 2, $\mu_{y}=17.56 \mathrm{~N} / \mathrm{mm}^{2}, y=15 \mathrm{~N} / \mathrm{mm}^{2}$

$\delta_{y}=0.1533$

From equation (13),

$\sigma_{x}=\left(0.1533^{2}+0.0125\right)^{1 / 2}=0.189$

Using equation (16) and the parameters obtained from Tables 1 and 2,

$\beta=\left(\frac{0.34 \times 15}{0.67 \times 17.56}-1\right) \frac{1}{0.189}=-2.998$

\section{RESULTS AND DISCUSSION}

The result of performance evaluation of an ongoing building construction based on working stress design criteria is presented. The obtained value of geometric index $(\beta=2.998)$ is found to be far below the target geometric indices of 4.9 for beams in flexure, 3.6 for beams in shear, 4.5 for slabs and 3.9 for columns under dead-live load combination.

In conclusion, the reliability status (geometric index $\beta=2.998$ ) predicted based on the concept of working stress design criteria does not show promise of satisfactory performance of the structure in service and may result in loss of lives and damage of properties on collapse. The deteriorated structure is therefore, recommended for careful demolition to erect a new structural framework and supervision should be more stringent. The predicted geometric index value (2.998) is almost identical with the values obtained in the previous papers, showing the effectiveness of the formulated model in the prediction of reliability status of an 
ongoing building construction. This model can also be used to ascertain the structural integrity of other civil engineering structures.

\section{REFERENCES}

[1] Ranganathan, R. Structural Reliability, Analysis and Design, Jaico Publishing House, Mumbai, 1999.

[2] Theft-Christensen P. and Baker M.J. Structural Reliability and Theory and its Applications, SpringerVerlag, Berlin, 1982.

[3] Mori Y. and Ellingwood B.R. "Reliability-Based Service Life Assessment of Aging Concrete Structures." Journal of Structural Engineering, Vol. 119, No.5, 1993, pp. 1600-1621.

[4] Haugen, E.B. Probabilistic Approach to Design, John Wiley, New York, 1986.

[5] Melchers, R. Structural Reliability Analysis and Prediction. Second Edition, John Wiley and Sons, 1999.

[6] Villemeur, A. "Reliability, Maintenance and Safety Assessment." Vol.2, 1992, (John Wiley), Chichester.

[7] Wilkinson, S. Physical Control of Risk, (Witherby), London, 1992.

[8] Afolayan, J.O. "Probability based design of glued thin-webbed timber beams." Asian Journal of Civil Engineering (Building and Housing) Vol.6, Nos. 1-2, 2005, pp. 75-84.

[9] Freudenthal, A.M. "Safety and Probability of Structural Failure." Transactions, ASCE, Vol. 121, 1956, pp. $1337-1375$.

[10] BS: 81100. British Standard Code of practice for Plain and Reinforced Concrete ( $3^{\text {rd }}$ Revision) Indian Standards Institution, London, 1985, pp. 2-7.

[11] Sule, S. "Probabilistic Approach to Structural Appraisal of a Building during Construction." Nigerian Journal of Technology, Vol. 30, No.2, 2011, pp 149-153. 